\title{
Novel drugs against tuberculosis: a clinician's perspective
}

\author{
Ioana Diana Olaru', Florian von Groote-Bidlingmaier ${ }^{2}$, Jan Heyckendorf ${ }^{1}$, \\ Wing Wai Yew ${ }^{3}$, Christoph Lange ${ }^{1,4,5,6}$ and Kwok Chiu Chang ${ }^{7}$ \\ Affiliations: \\ ${ }^{1}$ Division of Clinical Infectious Diseases, Research Center Borstel, German Center for Infection Research, \\ Clinical Tuberculosis Center, Borstel, Germany. \\ ${ }^{2}$ Task Applied Science, Karl Bremer Hospital, Bellville, Cape Town, South Africa. \\ ${ }^{3}$ Stanley Ho Centre for Emerging Infectious Diseases, The Chinese University of Hong Kong, Hong Kong, \\ China. \\ ${ }^{4}$ International Health/Infectious Diseases, University of Lübeck, Lübeck, Germany. \\ ${ }^{5}$ Dept of Internal Medicine, University of Namibia School of Medicine, Windhoek, Namibia. \\ ${ }^{6}$ Dept of Medicine, Karolinska Institute, Stockholm, Sweden. \\ ${ }^{7}$ Tuberculosis and Chest Service, Dept of Health, Hong Kong, China. \\ Correspondence: \\ Christoph Lange, Clinical Infectious Diseases, Research Center Borstel, Parkallee 35, 23845 Borstel, \\ Germany. \\ E-mail: clangedff-borstel.de
}

ABSTRACT The United Nations Millennium Development Goal of reversing the global spread of tuberculosis by 2015 has been offset by the rampant re-emergence of drug-resistant tuberculosis, in particular fluoroquinolone-resistant multidrug-resistant and extensively drug-resistant tuberculosis. After decades of quiescence in the development of antituberculosis medications, bedaquiline and delamanid have been conditionally approved for the treatment of drug-resistant tuberculosis, while several other novel compounds (AZD5847, PA-824, SQ109 and sutezolid) have been evaluated in phase II clinical trials. Before novel drugs can find their place in the battle against drug-resistant tuberculosis, linezolid has been compassionately used with success in the treatment of fluoroquinolone-resistant multidrug-resistant tuberculosis. This review largely discusses six novel drugs that have been evaluated in phase II and III clinical trials, with focus on the clinical evidence for efficacy and safety, potential drug interactions, and prospect for using multiple novel drugs in new regimens.

@ERSpublications

A review of the efficacy, safety, and potential of new drugs to improve TB therapy from the perspective of clinicians http://ow.ly/Das5l 


\section{Introduction}

Despite the advent of rifampicin and pyrazinamide almost half a century ago, tuberculosis (TB) has remained one of the leading causes of death worldwide [1-6]. Compared with HIV infection, there has been complacency and a lack of interest in TB drug development until the turn of the century. Notwithstanding the recognition of the standard 6-month regimen for drug-susceptible TB as "short-course" [6-11], 6 months is by no means short in comparison with most other bacterial diseases [12].

Not unexpectedly, the United Nations Millennium Development Goal of reversing the global spread of TB by 2015 has been offset by the rampant emergence of multidrug-resistant (MDR) and extensively drug-resistant (XDR) strains of Mycobacterium tuberculosis (fig. 1) [12-15]. Primarily occurring as a result of inadequate treatment, particularly in settings with low cure rates and high rates of default and relapse, MDR-TB refers to TB with bacillary resistance to both isoniazid and rifampicin, and XDR-TB, a subgroup of MDR-TB with additional resistance to any fluoroquinolone and at least one second-line injectable agent. In some areas of Eastern Europe, MDR-TB was found in $20 \%$ to $45 \%$ of all strains of M. tuberculosis isolated from patients [15].

MDR-TB poses problems for the global control of TB. Using second-line treatment regimens in programme settings, the overall cure rate is approximately $60 \%$ for MDR-TB, and $40 \%$ for XDR-TB [16]. Corresponding rates in the current surveillance data from Europe were $32 \%$ and $19 \%$ of patients, respectively, which are not better than spontaneous cure rates of TB [17]. Routine use of the World Health Organization (WHO) category II regimen for programmatic management of previously treated patients can fuel the spread of MDR-TB $[18,19]$. Although second-line treatment-naïve patients with MDR-TB, often caused by fluoroquinolone-susceptible strains of $M$. tuberculosis, may be successfully treated within 9 to 12 months using second-line regimens that contain high-dose later-generation fluoroquinolone [20], the WHO for many years recommended treatment for 18 months past culture conversion [14] with the latest update in 2011 recommending a total treatment duration of at least 20 months for MDR-TB [21]. Given the need to treat MDR-TB with expensive second-line drugs for a prolonged period [22], drug-resistant $\mathrm{TB}$ has drained invaluable resources, thereby offsetting global TB control efforts and threatening to subvert the WHO Stop TB Strategy by diverting attention and resources from the management of drug-susceptible cases, which still represent the main patient group worldwide [23].

Fluoroquinolone-resistant MDR-TB, including $\mathrm{XDR}-\mathrm{TB}$, is particularly difficult to treat. As later-generation fluoroquinolones (such as levofloxacin, moxifloxacin, gatifloxacin) may be efficacious against ofloxacin-resistant strains [24], WHO has recommended that later-generation fluoroquinolones be used in the treatment of XDR-TB [14]. A systematic review with meta-analysis of observational studies has corroborated this recommendation by demonstrating that later-generation fluoroquinolones significantly improve treatment outcomes of XDR-TB [25]. Before there is sufficient clinical evidence to support the use of novel drugs in the treatment of MDR-TB, linezolid has been compassionately used as a repurposed

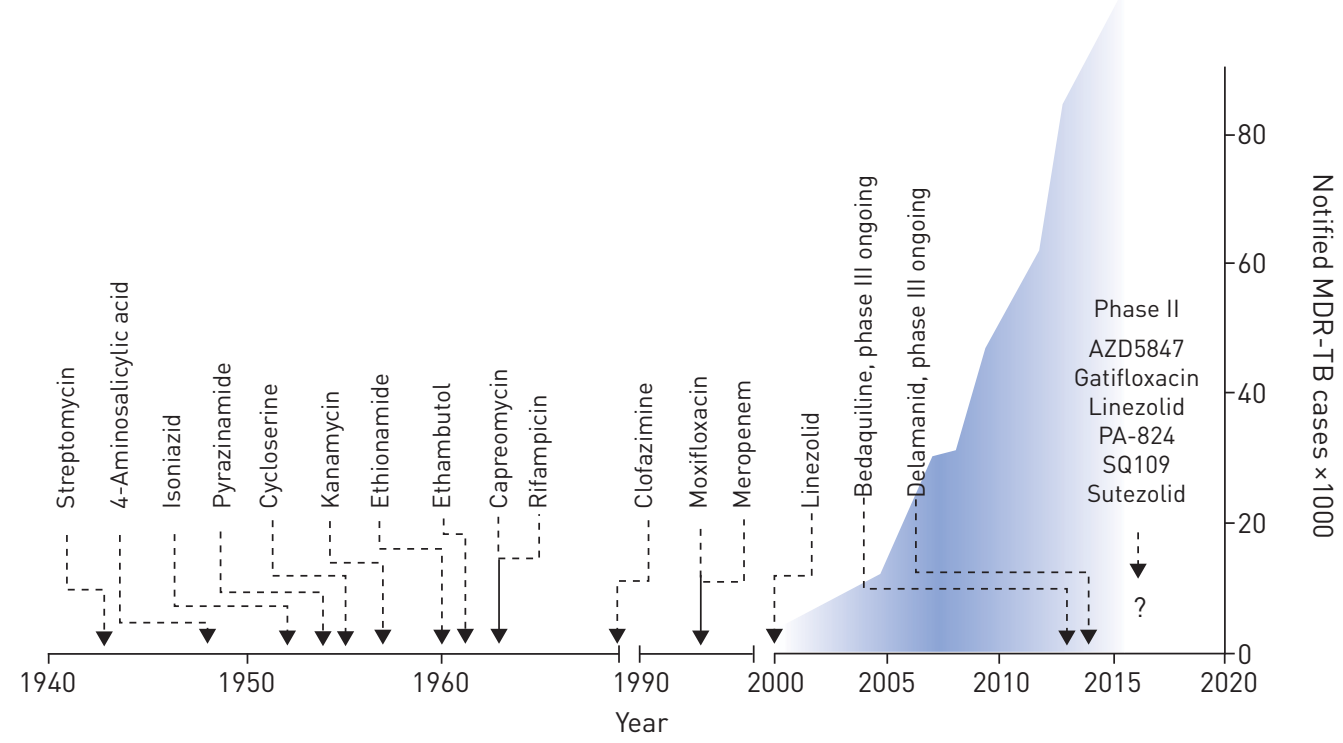

FIGURE 1 Anti-tuberculosis drug development and the increase in number of notified multidrug-resistant tuberculosis (MDR-TB) cases worldwide. 


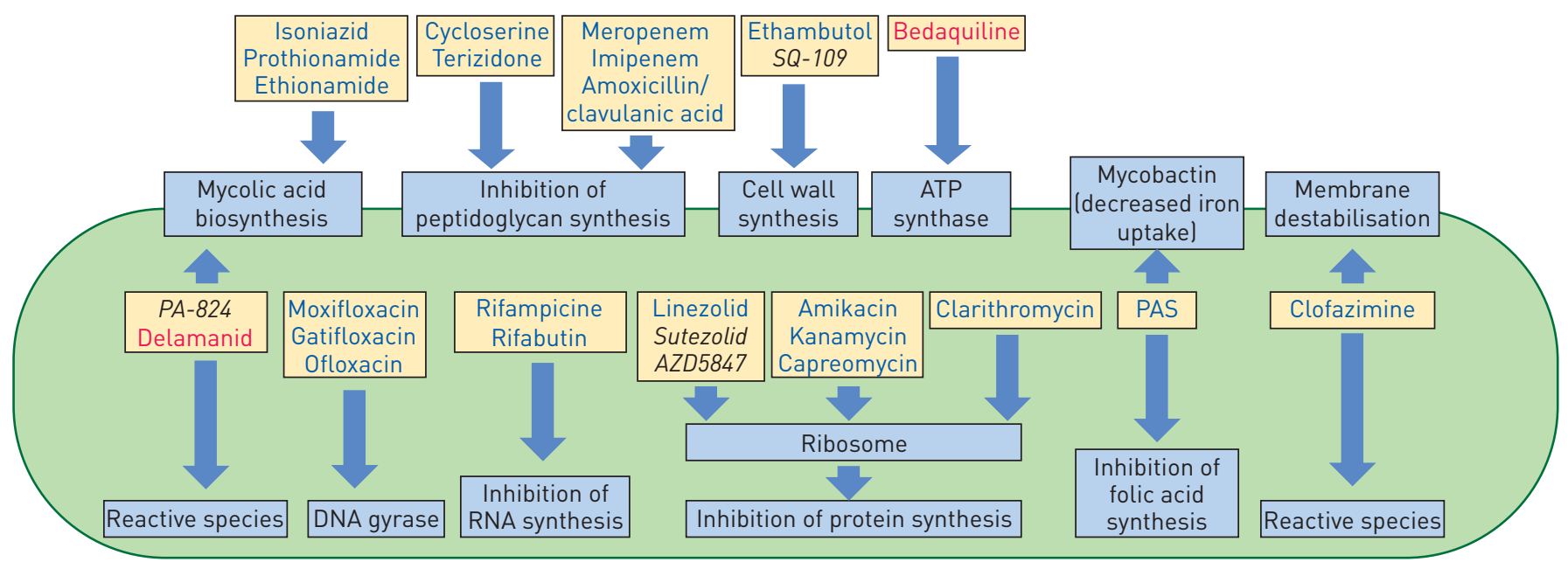

FIGURE 2 Mechanisms of action of anti-tuberculosis drugs. Drugs already in use are shown in blue, the newly approved drugs are shown in red and drugs undergoing clinical trials are shown in black.

agent in the treatment of fluoroquinolone-resistant MDR-TB with success [26-28] and a formal early bactericidal activity (EBA) trial of linezolid is in the final planning stage. A consensus for the management of patients with MDR-TB and XDR-TB has recently been released providing state-of-the-art treatment guidance [29].

The past decade has witnessed the advent of many novel compounds and drugs, of which six have been evaluated in phase II and III clinical trials (fig. 2 and table 1), and two (bedaquiline and delamanid) have been conditionally approved for the treatment of MDR-TB (table 1). Novel drugs will substantially influence future treatment of drug-resistant TB. An important issue is the emergence of bacillary resistance to new drugs, as has happened to streptomycin, isoniazid, and rifampicin after their introduction as a result of multiple avoidable factors [30,31]. It is thus imperative that novel drugs be used in adequate dosages and combinations under an optimal healthcare infrastructure [32] to forestall the occurrence of drug resistance.

To help clinicians better understand the latest development in the clinical management of drug-resistant $\mathrm{TB}$, this review mainly discusses six novel drugs that have been evaluated in phase II and III trials (bedaquiline, delamanid, PA-824, sutezolid, AZD5847 and SQ109), with focus on the clinical evidence for efficacy and safety, potentially important drug interactions, and prospect for using multiple novel drugs in new regimens.

\section{Novel drugs \\ Bedaquiline}

Bedaquiline is the first novel drug that has been conditionally approved for treating adult pulmonary MDR-TB by the US Food and Drug Administration (FDA) in December 2012, and by the European Medicines Agency (EMA) in March 2014 [33-36].

Bedaquiline (Sirturo, Janssens Pharmaceuticals) is a diarylquinoline with a new mechanism of action. By inhibiting the mycobacterial ATP synthase, thereby leading to intracellular ATP depletion [37], bedaquiline acts on both actively replicating and dormant mycobacteria, which still maintain residual ATP synthase activity [38]. Resistance develops through point mutations in the gene atpE, which encodes part of the ATP synthase, at predictable rates that are similar to those observed for rifampicin. Mutations conferring bacillary resistance to bedaquiline do not cause cross-resistance to other anti-TB drugs, except for clofazimine, possibly due to the upregulation of a multi-substrate efflux pump [39], which has also been found in clinical isolates [40]. With extensive tissue distribution and a long half-life, the recommended dose of bedaquiline for pulmonary MDR-TB in adults is $400 \mathrm{mg}$ once daily for 2 weeks, followed by $200 \mathrm{mg}$ three times weekly, for a total duration of 24 weeks [41].

The clinical evidence for using bedaquiline mainly came from one phase II clinical trial carried out in two stages [41], which showed that adding bedaquiline to a standard background MDR-TB treatment regimen significantly decreased the time to sputum culture conversion with a hazard ratio of 11.8 (95\% CI 2.361.3), significantly increased the proportion of patients with culture conversion from $9 \%$ to $48 \%$ at 8 weeks [42], and from $57.6 \%$ to $77.6 \%$ at 24 weeks [43], and nonsignificantly prevented the acquisition of additional resistance to other accompanying drugs [43]. 
TABLE 1 Profile of promising drug candidates for revolutionising treatment of multidrug-resistant (MDR) tuberculosis (TB)

\begin{tabular}{|c|c|c|c|c|c|c|c|}
\hline Drug & Drug class & Mode of action & $\begin{array}{l}\text { Mode of administration } \\
\text { and current dosage }\end{array}$ & Function & Toxicity & $\begin{array}{l}\text { Study } \\
\text { phase }\end{array}$ & Comment \\
\hline AZD5847 & Oxazolidinone & $\begin{array}{l}\text { Inhibition of microbial } \\
\text { protein synthesis (blocks } \\
50 S \text { ribosomal subunit) }\end{array}$ & $\begin{array}{l}\text { Oral, } 500-1200 \mathrm{mg} \\
\text { per day }\end{array}$ & Bactericidal & $\begin{array}{c}\text { Well tolerated, } \\
\text { non-severe } \\
\text { gastrointestinal } \\
\text { symptoms, white blood } \\
\text { cells count changes }\end{array}$ & Ila & $\begin{array}{l}\text { Ongoing EBA, including } \\
\text { dose-finding study }\end{array}$ \\
\hline $\begin{array}{l}\text { Bedaquiline } \\
\text { (TMC207) }\end{array}$ & Diarylquinoline & $\begin{array}{l}\text { Inhibition mycobacterial } \\
\text { ATP synthase }\end{array}$ & $\begin{array}{c}\text { Oral, } 400 \mathrm{mg} \text { per day for } \\
2 \text { weeks, } 200 \mathrm{mg} \text { three times } \\
\text { per week for } 22 \text { weeks }\end{array}$ & $\begin{array}{l}\text { Sterilising and } \\
\text { bactericidal }\end{array}$ & $\begin{array}{l}\text { QT-prolongation, } \\
\text { unexplained excess } \\
\text { mortality }\end{array}$ & III & $\begin{array}{l}\text { FDA approved, EMA } \\
\text { approved }\end{array}$ \\
\hline $\begin{array}{l}\text { Delamanid } \\
\text { (OPC-67683) }\end{array}$ & $\begin{array}{l}\text { Nitro-dihydro- } \\
\text { imidazooxazole }\end{array}$ & $\begin{array}{l}\text { Mycolic acid cell wall } \\
\text { inhibition }\end{array}$ & $\begin{array}{c}\text { Oral, } 100 \text { mg per day for } \\
2 \text { months, then } 200 \text { mg per } \\
\text { day for } 4 \text { months }\end{array}$ & Bactericidal & $\begin{array}{l}\text { Well tolerated, } \\
\text { QT-prolongation }\end{array}$ & III & EMA approved \\
\hline Gatifloxacin & Fluoroquinolone & DNA gyrase inhibition & Oral or intravenous & $\begin{array}{l}\text { Sterilising? and } \\
\text { bactericidal }\end{array}$ & $\begin{array}{l}\text { QT-prolongation, } \\
\text { dysglycaemia, } \\
\text { hallucination, liver } \\
\text { toxicity }\end{array}$ & II & $\begin{array}{l}\text { Market withdrawal in } 2006 \\
\text { due to risk of dysglycaemia }\end{array}$ \\
\hline Linezolid & Oxazolidinone & $\begin{array}{l}\text { Inhibition of microbial } \\
\text { protein synthesis (blocks } \\
50 S \text { ribosome subunit) }\end{array}$ & $\begin{array}{l}\text { Oral or intravenous, } \\
300-600 \text { mg per day }\end{array}$ & Bactericidal & $\begin{array}{l}\text { Myelosuppression, } \\
\text { peripheral neuropathy, } \\
\text { rhabdomyolysis }\end{array}$ & II & $\begin{array}{l}\text { Used for MDR/XDR-TB } \\
\text { since } 2005 \text { with good } \\
\text { efficacy but substantial } \\
\text { toxicity in long-term } \\
\text { treatment }\end{array}$ \\
\hline PA-824 & Nitroimidazole & $\begin{array}{l}\text { Reactive nitrogen } \\
\text { compound, cell wall } \\
\text { synthesis inhibition }\end{array}$ & Oral, $100-200$ mg per day & $\begin{array}{l}\text { Sterilising and } \\
\text { bactericidal }\end{array}$ & Well tolerated & Ilb & $\begin{array}{l}\text { Less expensive and easier } \\
\text { to co-administer with } \\
\text { antiviral drugs, with } \\
\text { potential for shortening } \\
\text { therapy using PA-824, } \\
\text { moxifloxacin and } \\
\text { pyrazinamide }\end{array}$ \\
\hline SQ109 & 1,2-ethylenediamine & $\begin{array}{l}\text { Cell wall synthesis } \\
\text { inhibition }\end{array}$ & Oral, 300 mg per day & Bactericidal & $\begin{array}{c}\text { No serious adverse } \\
\text { events, gastro-intestinal } \\
\text { predominantly }\end{array}$ & Ila & $\begin{array}{l}\text { Currently under evaluation } \\
\text { in MDR-TB patients in the } \\
\text { Russian Federation }\end{array}$ \\
\hline $\begin{array}{l}\text { Sutezolid } \\
\text { (PNU-100480) }\end{array}$ & Oxazolidinone & $\begin{array}{l}\text { Inhibition of microbial } \\
\text { protein synthesis (blocks } \\
50 S \text { ribosomal subunit) }\end{array}$ & Oral, $600-1200$ mg per day & Bactericidal & Well tolerated & II & $\begin{array}{c}\text { Besides concerns about } \\
\text { neurotoxicity after } \\
\text { prolonged use, } \\
\text { hepatotoxicity is a } \\
\text { potentially important } \\
\text { side-effect }\end{array}$ \\
\hline
\end{tabular}


At the end of the 120 weeks of evaluation period of the trial cure rates according to WHO definitions were $58 \%$ in the bedaquiline group and $32 \%$ in the placebo group $(\mathrm{p}=0.003)$ [44]. However, an unexplained increase in the risk of mortality was observed among the bedaquiline treatment group [43, 44]. Whether bedaquiline may shorten TB treatment, as has been suggested by animal studies [45, 46], should be interpreted with caution as bedaquiline was given with pyrazinamide, and in vitro data have also suggested that its EBA may be substantially dependent on concurrent use of pyrazinamide [47].

Besides an unexplained increase in the risk of mortality, bedaquiline may be associated with nausea, arthralgia, headache, liver injury, and QT prolongation [41]. Although QT prolongation cannot explain the significant increase in the risk of death, both the phase II clinical trial and another single-arm open-label trial have suggested that bedaquiline prolongs QT, and this risk is additively increased by concurrent use of other QT prolonging drugs [41]. It is thus important to take precaution in combining bedaquiline with other QT-prolonging drugs, which include clofazimine, fluoroquinolone (especially moxifloxacin [48]), and delamanid (see below) $[49,50]$.

\section{Delamanid}

Approved by EMA in November 2013 for conditional use in the treatment of MDR-TB, delamanid is the second (and the last one to date) novel drug that has been licenced for treating adult pulmonary MDR-TB $[51,52]$.

Delamanid (Deltyba, Otsuka Pharmaceuticals) is a derivative of metronidazole and a nitroimidazopyran (nitro-dihydro-imidazooxazole, 6-nitro-2,3-dihydroimidazo(2,1-b) oxazole). As a prodrug that requires activation for pharmacological activity, delamanid works by inhibiting mycolic acid biosynthesis. There is as yet no recommendation about dosage, pending the release of data from a completed multi-centre phase III trial that has evaluated use of delamanid $100 \mathrm{mg}$ twice daily for 2 months followed by $200 \mathrm{mg}$ once daily for 4 months. By sharing similar structure as nitro-dihydro-imidazooxazole derivatives, there may be cross-resistance between delamanid and PA-824 [53].

The clinical evidence for using delamanid is based on short-term phase II clinical trial data. A phase II multi-centre randomised placebo-controlled trial involving $481 \mathrm{MDR}-\mathrm{TB}$ patients showed that delamanid added to an optimal background regimen significantly increased the proportion with sputum culture conversion at 2 months from 29.6\% (placebo) to $45.4 \%$ (delamanid $100 \mathrm{mg}$ twice daily), and $41.9 \%$ (delamanid $200 \mathrm{mg}$ twice daily) [49]. An open-label extension of this phase II trial showed that delamanid use for more than 6 months in comparison with use for less than 2 months significantly increased the proportion with favourable outcomes (cure or treatment completion) from 55\% to $74.5 \%$ and significantly reduced mortality from $8.3 \%$ to $1.0 \%$ [54].

Delamanid significantly prolongs the QT interval from 3.8\% (placebo arm) to $9.9 \%$ (delamanid $100 \mathrm{mg}$ twice daily) and $13.1 \%$ (delamanid $200 \mathrm{mg}$ twice daily) [49]. Despite the lack of clinical events [49], it is thus important to increase vigilance when combining delamanid with bedaquiline, clofazimine, and fluoroquinolones (especially moxifloxacin).

\section{PA-824 (pretomanid)}

PA-824 is a bicyclic nitroimidazole and a prodrug that requires intracellular activation by a F420-dependent glucose-6-phosphate-dehydrogenase pathway. Activation produces a des-nitro metabolite that generates reactive nitrogen species (including NO) leading to a decrease in intracellular ATP and anaerobic killing (similar to the action of cyanide) [55, 56]. Although PA-824 seems to be more effective in anaerobic conditions [57], it also kills aerobically by inhibiting cell wall mycolic acid biosynthesis (similar to the action of isoniazid) [56]. As such, PA-824 expectedly showed activity against both replicating and non-replicating bacteria [58], and both drug-resistant and drug-susceptible TB [58-61]. Mutations have been identified in $f g d 1$ and $d d n$ [57, 62, 63], with cross-resistance to 5-nitrothiophenes (a tuberculostatic compound) [64] as well as delamanid [53]. With minimal inhibitory concentration (MIC) around $0.15-0.3 \mu \mathrm{g} \cdot \mathrm{mL}^{-1}[58,63]$, the activity of PA-824 is comparable to a combination of isoniazid and rifampicin in the continuation phase of a murine drug model [61]. As a large fraction of the active compound is plasma bound, its activity may be reduced in cavitary TB [65].

A phase II randomised controlled trial of EBA (NC-003) involving patients with smear-positive pulmonary TB suggested that the EBA of PA-824 was greatly dependent on its synergy with pyrazinamide, and a triad of PA-824, moxifloxacin and pyrazinamide gave the highest EBA, thereby suggesting its potential for further clinical trials [47]. The treatment efficacy of this triad has been evaluated in a phase II randomised controlled trial, pending the release of findings [66].

In humans, PA-824 has been well tolerated with constant pharmacodynamic parameters when given once daily, with the maximum serum drug level reached about $4-5 \mathrm{~h}$ following oral administration $[59,67,68]$. 
In a phase II dose-finding EBA study in which PA-824 was given over 14 days, the drug appeared safe and efficacious when given between $100 \mathrm{mg}$ and $200 \mathrm{mg}$ once daily [69]. PA-824 might induce a mild QT-interval prolongation [69] as well as a slight transient increase in creatinine that is not linked to a decrease in the glomerular filtration rate [59]. The effect of PA-824 and moxifloxacin in combination on the QT-interval is currently under evaluation [70].

\section{Sutezolid}

Sold to Sequella in July 2013, sutezolid (PNU-100480) is a linezolid analogue initially developed by Pfizer for evaluation of potentially better in vivo activity and less toxicity in comparison with linezolid [71]. With a substantially lower MIC against M. tuberculosis and reduction of MIC in acidic pH, sutezolid has demonstrated higher bactericidal activity than linezolid, as well as perhaps potential sterilising activity [72]. The whole-blood bactericidal activity of sutezoid $600 \mathrm{mg}$ twice daily is higher than that of linezolid $300 \mathrm{mg}$ once daily [73]. Although the EBA of sutezolid is significantly lower than that of the standard regimen [74] a whole blood bactericidal activity assay has demonstrated its synergistic activity with pyrazinamide [73].

Sutezolid does not appear to cause QT-interval prolongation or bone marrow suppression [73], although there are still concerns regarding potential neurotoxicity and hepatotoxicity. With a similar mitochondrial protein synthesis safety profile as linezolid $300 \mathrm{mg}$ once daily, prolonged use of sutezolid $600 \mathrm{mg}$ twice daily may cause peripheral neuropathy [27, 75]. A phase II randomised controlled trial of EBA has demonstrated the occurrence of transient and asymptomatic elevation of alanine transaminase among $14 \%$ patients in the sutezolid arm [74].

\section{AZD5847}

Like linezolid, AZD5847 is an oxazolidinone that inhibits mycobacterial protein synthesis by binding to the 50S ribosomal subunit; its in vitro bactericidal activity is superior to that of linezolid [76]. AZD5847 appears to be safe and well tolerated in healthy volunteers, with nausea being the most common adverse effect occurring at higher dosages [77]. A phase IIa trial of EBA with four different dosing strategies has been completed and results will hopefully be available in 2014 [78].

\section{SQ109}

Structurally related to ethambutol, SQ109 is a 1,2-ethylenediamine with a different mechanism of action and preserved activity against ethambutol-resistant $M$. tuberculosis isolates. Targeting the transmembrane transporter encoded by the $m m p L 3$ gene, SQ109 interferes with cell wall assembly [79].

In Russia and Kazakhstan, clinical trials of 6 months of SQ109 added to a background MDR-TB treatment regimen given over 18 months will be compared to the background regimen alone. However the number of patients is relatively small and the resulting data might not suffice to register SQ109 outside Russia and the Commonwealth of Independent States [80].

SQ109 appears to be safe and well tolerated in human studies. However, all SQ109-containing arms have been terminated in the multi-arm, multi-stage trial due to lack of sufficient efficacy.

\section{Interactions with antiviral drugs and azoles}

TB disease commonly coexists with HIV that requires simultaneous treatment with antiviral drugs. Azoles may be used among immunocompromised patients with coexisting fungal infection.

Bedaquiline is metabolised via the cytochrome (CYP) P450 3A4 leading to the formation of a much less active but potentially more toxic $N$-monodesmethyl metabolite [81]. In one study bedaquiline given with efavirenz, which is a CYP3A4 inducer [82], led to only a slight decrease in bedaquiline concentrations [83]. In contrast a nonlinear-mixed effects model evaluating the interaction between bedaquiline and efavirenz predicted that simultaneous treatment would lead to a $52 \%$ reduction in steady state concentrations of both bedaquiline and its metabolite. Reduced exposure could be prevented by adjusting the bedaquiline dose during concomitant treatment [81]. Co-administration of bedaquiline with nevirapine did not influence bedaquiline exposure [84]. Bedaquiline should be used with caution in patients receiving ritonavir-boosted lopinavir because co-administration was shown to cause a $22 \%$ increase in bedaquline exposure $[72,85]$.

It has been estimated that $30 \%$ of sutezolid and $20 \%$ of PA- 824 are also metabolised by CYP3A 4 [86]. Co-administration of PA-824 and efavirenz reduces the peak serum concentration and the area under concentration-time curve of PA-824 each by around 30\%. Clinical significance is unknown [73]. 
With no influence on the CYP enzymes, delamanid has a low potential for drug interactions. There are no clinically significant changes in drug exposure on co-administration of delamanid with efavirenz [87], ritonavir-boosted lopinavir or tenofovir [88].

SQ109 is neither activated nor metabolised via CYP3A4, but it is partially metabolised by CYP2C19, which is in turn strongly inhibited by fluconazole $[86,89]$. The clinical implications of these interactions are yet to be investigated.

\section{Clinical trials involving novel drugs used in combination}

To expedite the development of better TB treatment, it is probably necessary to use novel drugs in combination to formulate new $\mathrm{TB}$ drug regimens that rapidly reduce mortality and infectiousness with good bactericidal activity, maximally safeguard against the emergence of bacillary drug resistance with different mechanisms of action and, preferably, shorten treatment with prominent sterilising activity [90]. Given relatively scarce data on the use of novel drugs in combination, vigilance is always needed to closely monitor potential drug interactions and toxicity.

As bacillary resistance to fluoroquinolones [91, 92] and pyrazinamide [93, 94] is substantial among patients with MDR-TB, particularly in some geographical areas, it is probably better to use at least two, and perhaps three, novel drugs in combination, notwithstanding the preliminary promising activity from use of single novel agents, such as PA-824 alongside moxifloxacin and pyrazinamide [47]. This approach would help better safeguard against the amplification of bacillary resistance to both novel and existing TB drugs.

There are at least two conducted clinical trials involving novel drugs used in combination. The Global Alliance for TB Drug Development (TB Alliance) has sponsored a phase II randomised controlled trial of EBA (NC-001) involving patients with smear-positive pulmonary TB, which showed that the multi-agent EBA of PA-824 and bedaquiline was substantially lower than that of pyrazinamide with either PA-824 or bedaquiline [47]. The TB Alliance has also spearheaded a phase II randomised controlled trial involving patients with smear-positive pulmonary TB to further evaluate the EBA of PA-824 and bedaquiline in the presence of clofazimine, pyrazinamide or both [95].

There are at least two planned trials that will evaluate regimens containing multiple novel drugs: NiX-TB and MARVEL [78]. NiX-TB is a phase III non-controlled trial of a 6-month salvage regimen comprising linezolid, bedaquiline and PA-824. MARVEL is a phase II study of 8-week treatment with various combinations of sutezolid, bedaquiline, PA-824, pyrazinamide, levofloxacin and clofazimine.

A number of factors might have influenced the choice of combining novel drugs in clinical trials: in vitro data and findings from murine TB models about efficacy of certain combinations (table 2), concerns about life-threatening arrhythmia during concurrent use of novel (bedaquiline, delamanid) and existing (moxifloxacin, clofazimine) QT-prolonging drugs, synergistic activity of most novel drugs (bedaquiline, delamanid, PA-824, sutezolid) with pyrazinamide $[53,73,99,100]$, and possibly the relative difficulty in procuring delamanid and SQ109 in clinical trials.

\section{Novel designs for clinical trials}

Useful for screening and selecting potential drug candidates, in vitro data and animal models can never replace clinical trials in the evaluation of treatment efficacy and safety. Murine TB models have important disadvantages including the lack of full knowledge on the bioequivalent doses and also difference in pathogenetic mechanisms. There have been instances when observations derived from murine TB models

TABLE 2 Evidence from in vitro data or animal models that may affect the choice of combining novel drugs in clinical trials

Novel drugs in combination

Bedaquiline and PA-824

Bedaquiline, PA-824 and pyrazinamide

Bedaquiline, PA-824 and pyrazinamide

Bedaquiline and SQ109

Bedaquiline, SQ109 and pyrazinamide

Bedaquiline and sutezolid

Bedaquiline, sutezolid and SQ109

Bedaquiline, sutezolid and/or PA-824, and clofazimine

Sutezolid and SQ109

\section{Evidence}

Murine TB model: sterilising activity 45

Murine TB model: treatment over 4 months prevented relapse 45

In vitro: antagonistic effect due to PA-824

In vitro: synergy 96

Murine TB model: sterilising activity 89

Murine TB model: sterilising activity 46

In vitro: additive activity 97

Murine TB model: treatment over 4 months resulted in low relapse rates 46 In vitro: additive activity 98 
were discordant with those observed in human trials [101]. Additionally, given the current recommendation of treating MDR-TB for nearly 2 years [21], and the small sample size often used in animal experiments, it is difficult to evaluate sterilising activity in non-primate animal models.

The required sample size increases with the stage of drug development (table 3). In the absence of reliable surrogate markers for treatment outcomes, it is challenging to thoroughly evaluate treatment efficacy and safety in phase III clinical trials. In an attempt to expedite drug development, new methods such as EBA studies and multi-arm, multi-stage adaptive design have been adopted, although none can replace phase III trials.

EBA studies measure the fall in colony forming units (CFU) or the time to detection in liquid culture. This method provides reproducible results regarding efficacy although it does not reliably predict sterilising activity. The technique is mainly used for dose finding and preliminary evaluation of toxicity in a small sample [102] up to 14 days. Using this approach to evaluate PA-824, it has been shown that the mean multi-agent 14-day EBA of PA-824, moxifloxacin and pyrazinamide is comparable with that of the current standard treatment and significantly higher than those of bedaquiline, bedaquiline with pyrazinamide, and bedaquiline with PA-824 [47].

Previously used in other fields such as oncology, multi-arm, multi-stage adaptive design involves planned interim analyses at pre-specified time points to expedite the evaluation of different arms [103]. Weaker arms that do not meet pre-specified efficacy criteria are terminated, thereby focusing resources on alternative arms that are potentially more efficacious. Additionally, new arms can be flexibly added while the trial is in progress. A caveat is the need of reliable surrogate biomarkers at the pre-specified time points and an adequate number of comparison arms. Meanwhile, the hunt for reliable biomarkers and biosignatures that could help clinicians personalise TB treatment continues. Candidate markers are still in preclinical or early clinical evaluation; none can be recommended for routine use [12].

In the evaluation of new treatment combinations, it cannot be overemphasised that clinical trials be designed such that the risk of acquiring bacillary resistance to novel drugs is minimised.

\section{Future outlook}

In the coming decade, there are likely some newly developed anti-TB drugs that can substantially improve the current treatment of MDR/XDR-TB. Although the high efficacy of the newly developed anti-TB agents is unequivocal, the safety and tolerability of these novel drugs [104, 105] remain to be further evaluated in larger studies, and the resources that would be incurred are yet to be determined.

In harnessing repurposed agents to strengthen current treatment regimens for drug-resistant tuberculosis $[106,107]$ it is highly warranted to fathom novel approaches in the administration schedules that can concomitantly optimise the efficacy and safety of these drugs, especially linezolid. Further studies involving

TABLE 3 Current concepts of clinical trials involving investigational agents

\begin{tabular}{|c|c|c|}
\hline Phase & $\begin{array}{l}\text { Experimental } \\
\text { treatment duration }\end{array}$ & Characteristics \\
\hline Phase Ila & 14 days & $\begin{array}{l}\text { EBA studies, confirm the efficacy of novel agents or drug } \\
\text { combinations in humans in initial phase of treatment, dose } \\
\text { finding, assessment of pharmacokinetics and toxicity, do not } \\
\text { determine cure, single or dual site studies }\end{array}$ \\
\hline Phase Ilb & 8 weeks & $\begin{array}{l}\text { Intermediate stage, final dosage but not full duration, primary } \\
\text { end-point SCC at } 8 \text { weeks with often long-term follow-up, can } \\
\text { predict but do not prove cure }\end{array}$ \\
\hline Phase III & 6-9 months & $\begin{array}{l}\text { Final stage for registration, usually non-inferiority design in } \\
\text { drug-susceptible TB (sample size }>1000 \text { ), superiority design in } \\
\text { MDR-TB (sample size } 300-500 \text { ), evaluate sterilising activity of } \\
\text { regimens (sustained SCC), multi-site, multi-continent studies }\end{array}$ \\
\hline MAMS & $\begin{array}{c}\text { Various durations, like } \\
\text { phase II or III }\end{array}$ & $\begin{array}{l}\text { Adaptive trial design, multiple study arms run alongside one } \\
\text { control arm, poorly performing arms are discontinued at } \\
\text { pre-specified intervals, cost-effective }\end{array}$ \\
\hline
\end{tabular}

MAMS: multi-arm, multi-stage; EBA: early bactericidal activity; SCC: sputum culture conversion; TB: tuberculosis; MDR: multidrug-resistant. 
sizeable samples may be required to delineate the clinical role of other repurposed agents, which include clofazimine, meropenem and other carbapenems, thioridazine, and possibly co-trimoxazole [106].

Pharmacogenomics furnish great promise as an important tool to help in the evaluation of drug-associated toxicity [108], using different animal models including the mouse, possibly the zebra-fish [109] and non-human primates [110]. Such data might also have utility in clinical trials and settings to manage toxicity incurred by anti-TB drugs [111].

There are grounds for rekindling an interest in exploring the inhaled route of drug administration [112]. In the 1950s, streptomycin was first successfully used by an inhaled route to treat childhood TB with advanced radiographic lesions [113]. The advent of MDR-TB prompted further exploration using inhaled kanamycin and gentamicin $[112,114,115]$. The rationale was to attempt delivering a higher dose of the aminoglycoside to achieve better efficacy, without concomitant escalation in systemic toxicity, in these formidable drug-resistance settings. The preliminary results portrayed good patient outcome. A recent phase I, single-dose, dose-escalating study aimed at demonstrating the safety and tolerability of capreomycin, administered through a dry powder inhalational device in healthy subjects [116]. By the same token, much enthusiasm has been devoted to exploring the potential use of inhaled clofazimine in the treatment of pulmonary TB [112]. A recent study examined the efficacy of inhaled riminophenazine in dry powder leucine microparticles against M. tuberculosis in the human macrophage cell culture and aerosol-infected mouse model [117]. The inhaled route of delivering fluoroquinolones has also been studied in some preliminary experiments using ofloxacin [118] and levofloxacin [119], respectively. If a high-dose fluoroquinolone given by the oral route is limited by tolerability, as shown in the ongoing trials, an alternative approach may be to combine the oral and inhaled routes of drug delivery. Use of inhaled pyrazinamide proliposome for targeting alveolar macrophages has been recently evaluated [120]. A similar approach may be considered for novel drugs such as PA-824, which has been administered in dry powder aerosol to guinea pigs with less rapid clearance from the lungs by the inhalation route than oral delivery $[121,122]$. However, it might be simpler to licence the use of a repurposed agent through a new route of delivery than a novel drug.

Host immunity plays a pivotal role in the manifestation of TB disease. Adjunct immunotherapy, which includes host-directed therapies with immunoadjuvants [123-125], recombinant cytokines [126-128] or therapeutic vaccinations [128-138], should be further explored to possibly improve the treatment outcome of drug-resistant TB, especially difficult forms of MDR/XDR-TB [139].

TB with increasingly drug-resistant forms has clearly posed a gigantic threat to global health. With rapidly evolving development of new diagnostic tools and drugs, the battle against this old foe of mankind may not be insurmountable.

\section{References}

Yew WW, Lange C, Leung CC. Treatment of tuberculosis update 2010. Eur Respir J 2010; 37: 441-462.

World Health Organization. Treatment of Tuberculosis Guidelines. 4th Edn. Geneva, World Health Organization, 2010.

Iseman MD, Goble M. Treatment of tuberculosis. Adv Intern Med 1988; 33: 253-266.

American Thoracic Society, Center for Disease Control. Treatment of tuberculosis and other mycobacterial disease. Am Rev Respir Dis 1983; 127: 790-796.

5 Mitchison DA. Treatment of tuberculosis. The Mitchell Lecture 1979. J Roy Coll Phys London 1980; 14: 91-99.

6 Fox W, Mitchison DA. Short-course chemotherapy for pulmonary tuberculosis. Am Rev Respir Dis 1975; 111: 325-353.

7 Short-course chemotherapy in pulmonary tuberculosis. A controlled trial by the British Thoracic and Tuberculosis Association. Lancet 1975; 1: 119-124.

8 Short-course chemotherapy in pulmonary tuberculosis. A controlled trial by the British Thoracic and Tuberculosis Association. Lancet 1976; 2: 1102-1104.

9 Tripathy SP. Madras study of short-course chemotherapy in pulmonary tuberculosis. Bull Int Union Tuberc Lung Dis 1979; 54: 28-30.

10 Somner AR. Short-course chemotherapy in pulmonary tuberculosis. A controlled trial by the British Thoracic Association (third report). Lancet 1980; 1: 1182-1183.

11 Combs DL, O’Brien RJ, Geiter LJ. USPHS tuberculosis short-course chemotherapy trial 21: effectiveness, toxicity, and acceptability. Ann Intern Med 1990; 112: 397-406.

12 Heyckendorf J, Olaru ID, Ruhwald M, et al. Getting personal perspectives on individualized treatment duration in multidrug-resistant and extensively drug-resistant tuberculosis. Am J Respir Crit Care Med 2014; 190: 374-383.

13 World Health Organization. Management of MDR-TB: a Field Guide: a Companion Document to Guidelines for Programmatic Management of Drug-resistant Tuberculosis: Integrated Management of Adolescent and Adult Illness (IMAI). Geneva, World Health Organization, 2009.

14 World Health Organization. Guidelines for the Programmatic Management of Drug-resistant Tuberculosis. Emergency Update 2008. Geneva, World Health Organization, 2008.

15 World Health Organization. Global Tuberculosis Report 2012. Geneva, World Health Organization, 2012.

16 Falzon D, Gandhi N, Migliori GB, et al. Resistance to fluoroquinolones and second-line injectable drugs: impact on multidrug-resistant TB outcomes. Eur Respir J 2013; 42: 156-168. 
van der Werf MJ, Kodmon C, Hollo V, et al. Drug resistance among tuberculosis cases in the European Union and European Economic Area, 2007 to 2012. Euro Surveill 2014; 19: 20733.

Ponce M, Ugarte-Gil C, Zamudio C, et al. Additional evidence to support the phasing-out of treatment category II regimen for pulmonary tuberculosis in Peru. Trans $R$ Soc Trop Med Hyg 2012; 106: 508-510.

Matthys F, Rigouts L, Sizaire V, et al. Outcomes after chemotherapy with WHO category II regimen in a population with high prevalence of drug resistant tuberculosis. PLoS One 2009; 4: e7954.

Van Deun A, Maug AKJ, Salim MAH, et al. Short, highly effective, and inexpensive standardized treatment of multidrug-resistant tuberculosis. Am J Respir Crit Care Med 2010; 182: 684-692.

World Health Organization. Definitions and Reporting Framework for Tuberculosis - 2013 Revision. Geneva, World Health Organization, 2013.

Günther G, Gomez GB, Lange C, etal. Availability, price and affordability of anti-tuberculosis drugs in Europe: a TBNET survey. Eur Respir J 2015; 45: 1081-1089.

Chang KC, Dheda K. Rationalizing use of fluoroquinolones and pyrazinamide in the battle against multidrug-resistant tuberculosis. Am J Respir Crit Care Med 2013; 188: 10-11.

Yew WW, Chan CK, Leung CC, et al. Comparative roles of levofloxacin and ofloxacin in the treatment of multidrug-resistant tuberculosis: preliminary results of a retrospective study from Hong Kong. Chest 2003; 124: 1476-1481.

Jacobson KR, Tierney DB, Jeon CY, et al. Treatment outcomes among patients with extensively drug-resistant tuberculosis: systematic review and meta-analysis. Clin Infect Dis 2010; 51: 6-14.

Migliori GB, Eker B, Richardson MD, et al. A retrospective TBNET assessment of linezolid safety, tolerability and efficacy in multidrug-resistant tuberculosis. Eur Respir J 2009; 34: 387-393.

Koh WJ, Kang YR, Jeon K, et al. Daily $300 \mathrm{mg}$ dose of linezolid for multidrug-resistant and extensively drug-resistant tuberculosis: updated analysis of 51 patients. J Antimicrob Chemother 2012; 67: 1503-1507.

Chang KC, Yew WW, Cheung SW, et al. Can intermittent dosing optimize prolonged linezolid treatment of difficult multidrug-resistant tuberculosis? Antimicrob Agents Chemother 2013; 57: 3445-3449.

Lange C, Abubakar I, Alffenaar JW, et al. Management of patients with multidrug-resistant/extensively drug-resistant tuberculosis in Europe: a TBNET consensus statement. Eur Respir J 2014; 44: 23-63.

Streptomycin treatment of pulmonary tuberculosis. Br Med J 1948; 2: 769-782.

Treatment of pulmonary tuberculosis with isoniazid; an interim report to the Medical Research Council by their Tuberculosis Chemotherapy Trials Committee. Br Med J 1952; 2: 735-746.

Cegielski JP, Dalton T, Yagui M, et al. Extensive drug resistance acquired during treatment of multidrug-resistant tuberculosis. Clin Infect Dis 2014; 59: 1049-1063.

Cohen J. Infectious disease. Approval of novel TB drug celebrated-with restraint. Science 2013; $339: 130$.

European Medicines Agency, Press Release. European Medicines Agency Recommends Approval of a New Medicine for Multidrug-resistant Tuberculosis. http://www.ema.europa.eu/ema/index.jsp?curl=pages/news_and_ events/news/2013/12/news_detail_001999.jsp\&mid=WC0b01ac058004d5c1 December 20, 2013. Date last accessed: August 29, 2014.

Johnson and Johnson, Press Release. SIRTURO (bedaquiline) Receives Conditional Approval in the European Union for the Treatment of Multi-drug Resistant Tuberculosis. www.investor.jnj.com/releasedetail.cfm? ReleaseID=831021 March 6, 2014. Date last accessed: July 24, 2014.

US Food and Drug Administration. FDA News Release on Bedaquiline Approval. www.fda.gov/newsevents/ newsroom/pressannouncements/ucm333695.htm December 31, 2012. Date last accessed: August 29, 2014.

Andries K, Verhasselt P, Guillemont J, et al. A diarylquinoline drug active on the ATP synthase of Mycobacterium tuberculosis. Science 2005; 307: 223-227.

Koul A, Vranckx L, Dendouga N, et al. Diarylquinolines are bactericidal for dormant mycobacteria as a result of disturbed ATP homeostasis. J Biol Chem 2008; 283: 25273-25280.

Hartkoorn RC, Uplekar S, Cole ST. Cross-resistance between clofazimine and bedaquiline through upregulation of MmpL5 in Mycobacterium tuberculosis. Antimicrob Agents Chemother 2014; 58: 2979-2981.

Andries K, Villellas C, Coeck N, et al. Acquired resistance of Mycobacterium tuberculosis to bedaquiline. PLoS One 2014; 9: e102135.

Provisional CDC Guidelines for the Use and Safety Monitoring of Bedaquiline Fumarate (Sirturo) for the Treatment of Multidrug-Resistant Tuberculosis. MMWR Recomm Rep 2013; 62: 1-12.

Diacon AH, Pym A, Grobusch M, et al. The diarylquinoline TMC207 for multidrug-resistant tuberculosis. $N$ Engl J Med 2009; 360: 2397-2405.

Diacon AH, Donald PR, Pym A, et al. Randomized pilot trial of eight weeks of bedaquiline (TMC207) treatment for multidrug-resistant tuberculosis: long-term outcome, tolerability, and effect on emergence of drug resistance. Antimicrob Agents Chemother 2012; 56: 3271-3276.

Diacon AH, Pym A, Grobusch MP, et al. Multidrug-resistant tuberculosis and culture conversion with bedaquiline. N Engl J Med 2014; 371: 723-732.

Tasneen R, Li SY, Peloquin CA, et al. Sterilizing activity of novel TMC207- and PA-824-containing regimens in a murine model of tuberculosis. Antimicrob Agents Chemother 2011; 55: 5485-5492.

Williams K, Minkowski A, Amoabeng O, et al. Sterilizing activities of novel combinations lacking first- and second-line drugs in a murine model of tuberculosis. Antimicrob Agents Chemother 2012; 56: 3114-3120.

Diacon AH, Dawson R, von Groote-Bidlingmaier F, et al. 14-day bactericidal activity of PA-824, bedaquiline, pyrazinamide, and moxifloxacin combinations: a randomised trial. Lancet 2012; 380: 986-993.

Van Bambeke F, Tulkens PM. Safety profile of the respiratory fluoroquinolone moxifloxacin: comparison with other fluoroquinolones and other antibacterial classes. Drug Saf 2009; 32: 359-378.

Gler MT, Skripconoka V, Sanchez-Garavito E, et al. Delamanid for multidrug-resistant pulmonary tuberculosis. N Engl J Med 2012; 366: 2151-2160.

Dannemann BR, Bakare N, De Marez T, et al. Corrected QT Interval (QTcF) Prolongation in a Phase 2 Open-label Trial of TMC207 Plus Background Regimen (BR) as Treatment for MDR-TB: Effect of Co-administration with Clofazimine (CFZ). 53rd Interscience Conference on Antimicrobial Agents and Chemotherapy: Abstract A1259. www.icaaconline.com/php/icaac2013abstracts/data/papers/2012/A/2012_A-1259. htm 
51 European Medicines Agency. Summary of Opinion. Delamanid. www.ema.europa.eu/docs/en_GB/document_ library/Summary_of_opinion_-_Initial_authorisation/human/002552/WC500155458.pdf November 21, 2013. Date last accessed: July 24, 2014.

52 European Medicines Agency. Deltyba Product Infomation. www.ema.europa.eu/docs/en_GB/document_library/ EPAR_-_Product_Information/human/002552/WC500166232.pdf Date last accessed: July 24, 2014.

53 Matsumoto M, Hashizume H, Tomishige T, et al. OPC-67683, a nitro-dihydro-imidazooxazole derivative with promising action against tuberculosis in vitro and in mice. PLoS Med 2006; 3: e466.

54 Skripconoka V, Danilovits M, Pehme L, et al. Delamanid improves outcomes and reduces mortality in multidrug-resistant tuberculosis. Eur Respir J 2013; 41: 1393-1400.

55 Singh R, Manjunatha U, Boshoff HIM. PA-824 kills nonreplicating Mycobacterium tuberculosis by intracellular NO release. Science 2008; 322: 1392-1395.

56 Manjunatha U, Boshoff HI, Barry CE. The mechanism of action of PA-824 novel insights from transcriptional profiling. Commun Integr Biol 2009; 215-218.

57 Somasundaram S, Anand RS, Venkatesan P, et al. Bactericidal activity of PA-824 against Mycobacterium tuberculosis under anaerobic conditions and computational analysis of its novel analogues against mutant Ddn receptor. BMC Microbiol 2013; 13: 218-218.

58 Stover CK, Warrener P, VanDevanter DR, et al. A small-molecule nitroimidazopyran drug candidate for the treatment of tuberculosis. Nature 2000; 405: 962-966.

59 Ginsberg AM, Laurenzi MW, Rouse DJ, et al. Safety, tolerability, and pharmacokinetics of PA-824 in healthy subjects. Antimicrob Agents Chemother 2009; 53: 3720-3725.

60 Lenaerts AJ, Gruppo V, Marietta KS, et al. Preclinical testing of the nitroimidazopyran PA-824 for activity against Mycobacterium tuberculosis in a series of in vitro and in vivo models. Antimicrob Agents Chemother 2005; 49: 2294-2301.

61 Tyagi S, Nuermberger E, Yoshimatsu T, et al. Bactericidal activity of the nitroimidazopyran PA-824 in a murine model of tuberculosis. Antimicrob Agents Chemother 2005; 49: 2289-2293.

62 Feuerriegel S, Köser CU, Baù D, et al. Impact of Fgd1 and ddn diversity in Mycobacterium tuberculosis complex on in vitro susceptibility to PA-824. Antimicrob Agents Chemother 2011; 55: 5718-5722.

63 Manjunatha UH, Boshoff $\mathrm{H}$, Dowd CS, et al. Identification of a nitroimidazo-oxazine-specific protein involved in PA-824 resistance in Mycobacterium tuberculosis. Proc Natl Acad Sci USA 2006; 103: 431-436.

64 Hartkoorn RC, Ryabova OB, Chiarelli LR, et al. Mechanism of action of 5-nitrothiophenes against Mycobacterium tuberculosis. Antimicrob Agents Chemother 2014; 58: 2944-2947.

65 Hu Y, Coates ARM Mitchison DA Comparison of the sterilising activities of the nitroimidazopyran PA-824 and moxifloxacin against persisting Mycobacterium tuberculosis. Int J Tuberc Lung Dis 2008; 12: 69-73.

66 Global Alliancefor TB. Drug Development. Evaluation of 8 Weeks of Treatment With the Combination of Moxifloxacin, PA-824 and Pyrazinamide in Patients With Drug Sensitive and Multi Drug-resistant Pulmonary Tuberculosis (TB) 2013. http//clinicaltrials.gov/ct2/show/NCT01498419 Date last updated: March 12, 2013.

67 Ginsberg AM, Laurenzi MW, Rouse DJ, et al. Assessment of the effects of the nitroimidazo-oxazine PA-824 on renal function in healthy subjects. Antimicrob Agents Chemother 2009; 53: 3726-3733.

68 Diacon AH, Dawson R, Hanekom M, et al. Early bactericidal activity and pharmacokinetics of PA-824 in smear-positive tuberculosis patients. Antimicrob Agents Chemother 2010; 54: 3402-3407.

69 Diacon AH, Dawson R, du Bois J, et al. Phase II dose-ranging trial of the early bactericidal activity of PA-824. Antimicrob Agents Chemother 2012; 56: 3027-3031.

70 Effect of PA-824 and of PA-824 Plus Moxifloxacinon the QTc Interval in Healthy Volunteers. http:// clinicaltrials.gov/ct2/show/NCT01674218?term=NCT01674218\&rank=1 Date last updated: February 14, 2013. Date last accessed: April 8, 2014.

71 Barbachyn MR, Hutchinson DK, Brickner SJ, et al. Identification of a novel oxazolidinone (U-100480) with potent antimycobacterial activity. J Med Chem 1996; 39: 680-685.

72 Yip PC, Kam KM, Lam ET, et al. In vitro activities of PNU-100480 and linezolid against drug-susceptible and drug-resistant Mycobacterium tuberculosis isolates. Int J Antimicrob Agents 2013; 42: 96-97.

73 Wallis RS, Jakubiec W, Kumar V, et al. Biomarker-assisted dose selection for safety and efficacy in early development of PNU-100480 for tuberculosis. Antimicrob Agents Chemother 2011; 55: 567-574.

74 Wallis RS, Dawson R, Friedrich SO, et al. Mycobactericidal activity of sutezolid (PNU-100480) in sputum (EBA) and blood (WBA) of patients with pulmonary tuberculosis. PLoS One 2014; 9: e94462.

75 Lee M, Lee J, Carroll MW, et al. Linezolid for treatment of chronic extensively drug-resistant tuberculosis. $N$ Engl J Med 2012; 367: 1508-1518.

76 Balasubramanian V, Solapure S, Iyer H, et al. Bactericidal activity and mechanism of action of AZD5847, a novel oxazolidinone for treatment of tuberculosis. Antimicrob Agents Chemother 2014; 58: 495-502.

77 Reele S, Xiao AJ, Das S, et al. 14 Day Multiple Ascending Dose Study with AZD5847 Is Well Tolerated at Predicted Exposure for Treatment of Tuberculosis (TB). 51st Interscience Conference on Antimicrobial Agents and Chemotherapy: Abstract A11735. http://www.abstractsonline.com/plan/ViewAbstract.aspx?mID=2789\&sKey=0b498 641-f10a-4936-b80c-d274ffe4b143\&cKey=2271e63a-2cdc-4956-b7b0-6f7dc642b346\&mKey=0c918954-d607-46a7-807344f4b537a439

78 Phase 2a EBA Trial of AZD5847. http://clinicaltrials.gov/show/NCT01516203 Date last updated: April 16, 2014. Date last accessed: June 29, 2014

79 Tahlan K, Wilson R, Kastrinsky DB, et al. SQ109 targets MmpL3, a membrane transporter of trehalose monomycolate involved in mycolic acid donation to the cell wall core of Mycobacterium tuberculosis. Antimicrob Agents Chemother 2012; 56: 1797-1809.

80 The HIV i-Base/Treatment Action Group. 2013 Pipeline Report: HIV, Hepatitis C Virus (HCV), and Tuberculosis (TB) Drugs, Diagnostics, Vaccines, Preventive Technologies, Research Toward a Cure, and Immune-Based and Gene Therapies in Development. Benzacar A, Horn T, Morgan S, eds. London, HIV i-Base, 2013.

81 Svensson EM, Aweeka F, Park JG, et al. Model-based estimates of the effects of efavirenz on bedaquiline pharmacokinetics and suggested dose adjustments for patients coinfected with HIV and tuberculosis. Antimicrob Agents Chemother 2013; 57: 2780-2787. 
Mouly S, Lown KS, Kornhauser D, et al. Hepatic but not intestinal CYP3A4 displays dose-dependent induction by efavirenz in humans. Clin Pharm Ther 2002; 72: 1-9.

Dooley KE, Park JG, Swindells S, et al. Safety, tolerability, and pharmacokinetic interactions of the antituberculous agent TMC207 (bedaquiline) with efavirenz in healthy volunteers: AIDS Clinical Trials Group Study A5267. J Acquir Immune Defic Syndr 2012; 59: 455-462.

Van Heeswijk R, Vandevoorde A, Meyvisch P, et al. The Effect of Nevirapine on the Pharmacokinetics of TMC207, an Investigational Antimycobacterial Agent, in HIV-1-infected Subjects. 6th IAS Conference on HIV Pathogenesis, Treatment and Prevention: Abstract MOPE172. http://pag.ias2011.org/abstracts.aspx?aid=1350.

Sow FB, Alvarez GR, Gross RP, et al. Role of STAT1, NF-kappaB, and C/EBPbeta in the macrophage transcriptional regulation of hepcidin by mycobacterial infection and IFN-gamma. J Leukoc Biol 2009; 86: $1247-1258$.

Dooley KE, Kim PS, Williams SD, et al. Pharmacology Research Priorities. AIDS Res Treat 2012; 2012: 874083.

Petersen C, Paccaly A, Kim J, et al. Delamanid, a New Drug for Multi-drug Resistant Tuberculosis (MDR-TB), and Efavirenz Do Not Show Clinically Relevant Drug Interactions in Healthy Subjects. 52nd Interscience Conference on Antimicrobial Agents and Chemotherapy: Abstract A-1255. http://www.abstractsonline.com/Plan/ ViewAbstract.aspx?sKey=a96a704b-ee24-44df-8955-f1688acf7663\&cKey=0be05c32-0d75-4e82-9117-0b465a0e1daf \&mKey=\{6B114A1D-85A4-4054-A83B-04D8B9B8749F $\}$

Wayne LG, Sramek HA. Metronidazole is bactericidal to dormant cells of Mycobacterium tuberculosis. Antimicrob Agents Chemother 1994; 38: 2054-2058.

Sacksteder KA, Protopopova M Barry CE 3rd, et al. Discovery and development of SQ109: a new antitubercular drug with a novel mechanism of action. Future Microbiol 2012; 7: 823-837.

Spigelman M, Woosley R, Gheuens J. New initiative speeds tuberculosis drug development: novel drug regimens become possible in years, not decades. Int J Tuberc Lung Dis 2010; 14: 663-664.

World Health Organization. Anti-tuberculosis Drug Resistance in the World: Fourth Global Report. Geneva, World Health Organization, 2008.

Dalton T, Cegielski P, Akksilp S, et al. Prevalence of and risk factors for resistance to second-line drugs in people with multidrug-resistant tuberculosis in eight countries: a prospective cohort study. Lancet 2012; 380: 1406-1417. Chang KC, Yew WW, Zhang Y. Pyrazinamide susceptibility testing in Mycobacterium tuberculosis: a systematic review with meta-analyses. Antimicrob Agents Chemother 2011; 55: 4499-4505.

Pierre-Audigier C, Surcouf C, Cadet-Daniel V, et al. Fluoroquinolone and pyrazinamide resistance in multidrugresistant tuberculosis. Int J Tuberc Lung Dis 2012; 16: 221-223.

Global Alliancefor TB. Drug Development. Evaluation of Early Bactericidal Activity in Pulmonary Tuberculosis With Clofazimine (C)-TMC207 (J)-PA-824 (Pa)-Pyrazinamide (Z) (NC-003). http://clinicaltrials.gov/ct2/show/ NCT01691534?term=NCT01691534\&rank=1 Date last updated: April 11, 2013.

Reddy VM, Einck L, Andries K, et al. In vitro interactions between new antitubercular drug candidates SQ109 and TMC207. Antimicrob Agents Chemother 2010; 54: 2840-2846.

Wallis RS, Jakubiec W, Mitton-Fry M, et al. Rapid evaluation in whole blood culture of regimens for XDR-TB containing PNU-100480 (sutezolid), TMC207, PA-824, SQ109, and pyrazinamide. PLoS One 2012; 7: e30479.

Reddy VM, Dubuisson T, Einck L, et al. SQ109 and PNU-100480 interact to kill Mycobacterium tuberculosis in vitro. J Antimicrob Chemother 2012; 67: 1163-1166.

Tasneen R, Tyagi S, Williams K, et al. Enhanced bactericidal activity of rifampin and/or pyrazinamide when combined with PA-824 in a murine model of tuberculosis. Antimicrob Agents Chemother 2008; 52: 3664-3668.

Ibrahim M, Andries K, Lounis N, et al. Synergistic activity of R207910 combined with pyrazinamide against murine tuberculosis. Antimicrob Agents Chemother 2007; 51: 1011-1015.

Mitchison DA, Chang KC. Experimental models of tuberculosis: can we trust the mouse? Am J Respir Crit Care Med 2009; 180: 201-202.

2 Diacon AH, Donald PR. The early bactericidal activity of antituberculosis drugs. Expert Rev Anti Infect Ther 2014; 12: 223-237.

Phillips PP, Gillespie SH, Boeree M, et al. Innovative trial designs are practical solutions for improving the treatment of tuberculosis. J Infect Dis 2012; 205: Suppl. 2: S250-S257.

Tiberi S, De Lorenzo S, Centis R, et al. Bedaquiline in MDR/XDR-TB cases: first experience on compassionate use. Eur Respir J 2014; 43: 289-292.

Deltyba: New Antibacterial for Multidrug-resistant Tuberculosis. http://www.mims.co.uk/deltyba-newantibacterial-multidrug-resistant-tuberculosis/infections-and-infestations/article/1298056. Date last updated: June 16, 2014. Date last accessed: July 24, 2014.

Alsaad N, Wilffert B, van Altena R, et al. Potential antimicrobial agents for the treatment of multidrug-resistant tuberculosis. Eur Respir J 2014; 43: 884-897.

Gunther G. Multidrug-resistant and extensively drug-resistant tuberculosis: a review of current concepts and future challenges. Clin Med 2014; 14: 279-285.

Agrawal YP, Rennert H. Pharmacogenomics and the future of toxicology testing. Clin Lab Med 2012; 32: 509-523.

Orellana-Paucar AM, Afrikanova T, Thomas J, et al. Insights from zebrafish and mouse models on the activity and safety of ar-turmerone as a potential drug candidate for the treatment of epilepsy. PLoS One 2013; 8: e81634-

0 Lin PL, Coleman T, Carney JP, et al. Radiologic responses in cynomolgous macaques for assessing tuberculosis chemotherapy regimens. Antimicrob Agents Chemother 2013; 57: 4237-4244.

Ramachandran G, Swaminathan S. Role of pharmacogenomics in the treatment of tuberculosis: a review. Pharmacogenomics Pers Med 2012; 5: 89-98.

2 Misra A, Hickey AJ, Rossi C, et al. Inhaled drug therapy for treatment of tuberculosis. Tuberculosis 2011; 91: $71-81$.

Miller JB, Abramson HA, Ratner B. Aerosol streptomycin treatment of advanced pulmonary tuberculosis in children. Am J Dis Child 1950; 80: 207-237.

Sacks LV, Pendle S, Orlovic D, et al. Adjunctive salvage therapy with inhaled aminoglycosides for patients with persistent smear-positive pulmonary tuberculosis. Clin Infect Dis 2001; 32: 44-49. 
115 Justo OR, Moraes AM. Kanamycin incorporation in lipid vesicles prepared by ethanol injection designed for tuberculosis treatment. J Pharm Pharmacol 2005; 57: 23-30.

116 Dharmadhikari AS, Kabadi M, Gerety B, et al. single-dose, dose-escalating study of inhaled dry powder capreomycin: a new approach to therapy of drug-resistant tuberculosis. Antimicrob Agents Chemother 2013; 57: 2613-2619.

117 Verma RK, Germishuizen WA, Motheo MP, et al. Inhaled microparticles containing clofazimine are efficacious in treatment of experimental tuberculosis in mice. Antimicrob Agents Chemother 2013; 57: 1050-1052.

118 Park JH, Jin HE, Kim DD, et al. Chitosan microspheres as an alveolar macrophage delivery system of ofloxacin via pulmonary inhalation. Int J Pharm 2013; 441: 562-569.

119 Rojanarat W, Nakpheng T, Thawithong E, et al. Levofloxacin-proliposomes: opportunities for use in lung tuberculosis. Pharmaceutics 2012; 4: 385-412.

120 Rojanarat W, Nakpheng T, Thawithong E, et al. Inhaled pyrazinamide proliposome for targeting alveolar macrophages. Drug Deliv 2012; 19: 334-345.

121 Garcia-Contreras L, Sung JC, Muttil P, et al. Dry powder PA-824 aerosols for treatment of tuberculosis in guinea pigs. Antimicrob Agents Chemother 2010; 54: 1436-1442.

122 Sung JC, Garcia-Contreras L, Verberkmoes JL, et al. Dry powder nitroimidazopyran antibiotic PA-824 aerosol for inhalation. Antimicrob Agents Chemother 2009; 53: 1338-1343.

123 Efremenko YV, Arjanova OV, Prihoda ND, et al. Clinical validation of sublingual formulations of Immunoxel (Dzherelo) as an adjuvant immunotherapy in treatment of TB patients. Immunotherapy 2012; 4: 273-282.

124 Nunn A, Phillips PP, Abubakar I. Treatment of pulmonary tuberculosis. Curr Opin Pulm Med 2013; 19: 273-279.

125 Schon T, Lerm M, Stendahl O. Shortening the "short-course" therapy: insights into host immunity may contribute to new treatment strategies for tuberculosis. J Intern Med 2013; 273: 368-382.

126 Bourinbaiar AS, Mezentseva MV, Butov DA, et al. Immune approaches in tuberculosis therapy: a brief overview. Expert Rev Anti Infect Ther 2012; 10: 381-389.

127 Gao XF, Yang ZW, Li J. Adjunctive therapy with interferon-gamma for the treatment of pulmonary tuberculosis: a systematic review. Int J Infect Dis 2011; 15: e594-600.

128 Uhlin M, Andersson J, Zumla A, et al. Adjunct immunotherapies for tuberculosis. J Infect Dis 2012; 205 Suppl. 2: S325-S334.

129 Stanford J, Stanford C, Grange J. Immunotherapy with Mycobacterium vaccae in the treatment of tuberculosis. Front Biosci 2004; 9: 1701-1719.

130 von Reyn CF, Mtei L, Arbeit RD, et al. Prevention of tuberculosis in Bacille Calmette-Guerin-primed, HIVinfected adults boosted with an inactivated whole-cell mycobacterial vaccine. AIDS 2010; 24: 675-685.

131 Yang XY, Chen QF, Li YP, et al. Mycobacterium vaccae as adjuvant therapy to anti-tuberculosis chemotherapy in never-treated tuberculosis patients: a meta-analysis. PLoS One 2011; 6: e23826.

132 Efremenko YV, Butov DA, Prihoda ND, et al. Randomized, placebo-controlled phase II trial of heat-killed Mycobacterium vaccae (Longcom batch) formulated as an oral pill (V7). Hum Vaccin Immunother 2013; 9: $1852-1856$.

133 Butov DA, Efremenko YV, Prihoda ND, et al. Randomized, placebo-controlled phase II trial of heat-killed Mycobacterium vaccae (Immodulon batch) formulated as an oral pill (V7). Immunotherapy 2013; 5: 1047-1054.

134 Arjanova OV, Prihoda ND, Yurchenko LV, et al. Adjunct oral immunotherapy in patients with re-treated, multidrug-resistant or HIV-coinfected TB. Immunotherapy 2011; 3: 181-191.

135 Butov DA, Efremenko YV, Prihoda ND, et al. Adjunct immune therapy of first-diagnosed TB, relapsed TB, treatment-failed TB, multidrug-resistant TB and TB/HIV. Immunotherapy 2012; 4: 687-695.

136 Ahsan MJ, Garg SK, Vashishtha B, et al. Tuberculosis vaccines: hopes and hurdles. Infect Disord Drug Targets 2013; 13;3: 318-321.

137 Pitt JM, Blankley S, McShane H, et al. Vaccination against tuberculosis: how can we better BCG? Microb Pathog 2013; 58: 2-16.

138 Horvath $\mathrm{CN}$, Xing Z. Immunization strategies against pulmonary tuberculosis: considerations of $\mathrm{T}$ cell geography. Adv Exp Med Biol 2013; 783: 267-278.

139 Kaufmann SH, Lange C, Rao M, et al. Progress in tuberculosis vaccine development and host-directed therapiesa state of the art review. Lancet Respir Med 2014; 2: 301-320. 